\title{
Seeing ghosts: Negative body evaluation predicts overestimation of negative social feedback
}

Citation for published version (APA):

Alleva, J. M., Lange, W. G., Jansen, A., \& Martijn, C. (2014). Seeing ghosts: Negative body evaluation predicts overestimation of negative social feedback. Body Image, 11(3), 228-232.

https://doi.org/10.1016/j.bodyim.2014.03.001

Document status and date:

Published: 01/01/2014

DOI:

10.1016/j.bodyim.2014.03.001

Document Version:

Publisher's PDF, also known as Version of record

Document license:

Taverne

Please check the document version of this publication:

- A submitted manuscript is the version of the article upon submission and before peer-review. There can be important differences between the submitted version and the official published version of record.

People interested in the research are advised to contact the author for the final version of the publication, or visit the DOI to the publisher's website.

- The final author version and the galley proof are versions of the publication after peer review.

- The final published version features the final layout of the paper including the volume, issue and page numbers.

Link to publication

\footnotetext{
General rights rights.

- You may freely distribute the URL identifying the publication in the public portal. please follow below link for the End User Agreement:

www.umlib.nl/taverne-license

Take down policy

If you believe that this document breaches copyright please contact us at:

repository@maastrichtuniversity.nl

providing details and we will investigate your claim.
}

Copyright and moral rights for the publications made accessible in the public portal are retained by the authors and/or other copyright owners and it is a condition of accessing publications that users recognise and abide by the legal requirements associated with these

- Users may download and print one copy of any publication from the public portal for the purpose of private study or research.

- You may not further distribute the material or use it for any profit-making activity or commercial gain

If the publication is distributed under the terms of Article $25 \mathrm{fa}$ of the Dutch Copyright Act, indicated by the "Taverne" license above, 
Brief research report

\title{
Seeing ghosts: Negative body evaluation predicts overestimation of negative social feedback
}

\author{
Jessica M. Alleva ${ }^{a, *}$, Wolf-Gero Lange ${ }^{b}$, Anita Jansen ${ }^{a}$, Carolien Martijn ${ }^{a}$ \\ a Department of Clinical Psychological Science, Maastricht University, Maastricht, The Netherlands \\ ${ }^{\mathrm{b}}$ Department of Clinical Psychology \&'Behavioural Science Institute, Radboud University, Nijmegen, The Netherlands
}

\section{A R T I C L E I N F O}

\section{Article history:}

Received 25 November 2013

Received in revised form 10 March 2014

Accepted 10 March 2014

\section{Keywords:}

Body evaluation

Covariation bias

Social feedback

Cognitive processing

Interpersonal experiences

\begin{abstract}
A B S T R A C T
The current study investigated whether negative body evaluation predicts women's overestimation of negative social feedback related to their own body (i.e., covariation bias). Sixty-five female university students completed a computer task where photos of their own body, of a control woman's body, and of a neutral object, were followed by nonverbal social feedback (i.e., facial crowds with equal numbers of negative, positive, and neutral faces). Afterward, women estimated the percentage of negative, positive, and neutral social feedback that followed their own body, the control woman's body, and the neutral object. The findings provided evidence for a covariation bias: negative body evaluation predicted higher estimates of negative social feedback for women's own body, but not for the other stimuli. Additionally, the covariation bias was not explained by differences in how women interpreted the social feedback (the facial stimuli). Clinical implications of the covariation bias to body image are discussed.
\end{abstract}

(C) 2014 Elsevier Ltd. All rights reserved.

\section{Introduction}

Cognitive-behavioural perspectives on body image propose that body evaluation (i.e., satisfaction or dissatisfaction with one's body) has a profound influence on cognitive processing, and vice versa (see Cash, 2011, for a review). For example, individuals with negative body evaluation may demonstrate various distortions in cognitive processing, such as dichotomous thinking (e.g., "If I'm not a size 0 then I must be fat!"), biased social comparisons (e.g., with media models), and magnification/minimisation (e.g., of perceived flaws in appearance; Cash, 2011; Jakatdar, Cash, \& Engle, 2006). In turn, distortions in cognitive processing may serve to reinforce and maintain negative body evaluation (Williamson, White, YorkCrowe, \& Stewart, 2004).

Likewise, cognitive-behavioural perspectives propose that interpersonal experiences play a crucial role in shaping body evaluation (Cash, 2011). Social feedback, ranging from implicit body language and gaze to explicit comments and teasing, has the power to make individuals feel dissatisfied with their body (for details, see Carlson Jones, 2011; Cash \& Fleming, 2002; Fredrickson \& Roberts,

\footnotetext{
* Corresponding author at: Department of Clinical Psychological Science, Maastricht University, P.O. Box 616, 6200 MD Maastricht, The Netherlands. Tel.: +310433881609.

E-mail addresses: Jessica.Alleva@maastrichtuniversity.nl, j.m.alleva@gmail.com (J.M. Alleva).
}

1997; Tantleff-Dunn \& Lindner, 2011). In addition, negative body evaluation may also cause individuals to behave in ways that actually elicit negative social feedback from others (e.g., by avoiding eye contact, by not approaching others), thereby creating a selffulfilling prophecy that confirms their beliefs (e.g., "I really am fat and unapproachable!") and maintains negative body evaluation (Cash \& Fleming, 2002; Tantleff-Dunn \& Lindner, 2011).

In the present study, we sought to integrate the domains of cognitive processing and interpersonal experiences with regard to body evaluation. In particular, we investigated the role of negative body evaluation on covariation bias with regard to interpersonal experiences, which has not been investigated before.

Covariation bias is a distortion in cognitive processing whereby an individual overestimates the contingency between a certain stimulus and an aversive outcome, even when in reality the contingency is absent or is correlated in the opposite direction (Chapman \& Chapman, 1967). In the field of psychopathology, covariation bias has most often been studied with regard to anxiety. For example, experimental studies have shown that individuals with spider phobia overestimate the association between images of spiders and an electric shock (e.g., De Jong, Merckelbach, Arntz, \& Nijman, 1992; Tomarken, Mineka, \& Cook, 1989; Tomarken, Sutton, \& Mineka, 1995). Furthermore, there is also evidence to suggest that individuals with social anxiety disorder overestimate the relation between social stimuli (e.g., ambiguous social situations) and aversive outcomes (e.g., negative social feedback; Hermann, Ofer, \& Flor, 2004). Regardless of the context in which it is studied, covariation bias may 
have a direct and powerful influence on confirming danger expectations, enhancing fear, and maintaining psychological distress (De Jong, Van Den Hout, \& Merckelbach, 1995; Hirsch \& Clark, 2004).

We proposed that a covariation bias may also play a role in individuals with a negative body evaluation. Similar to covariation bias in individuals with social anxiety disorder, it could be that individuals with a negative body evaluation overestimate the relation between their own body (the stimulus) and negative social feedback (the aversive outcome). Consequently, this covariation bias may confirm negative expectations (e.g., "Everyone really does think that I am unattractive!") and maintain psychological distress (i.e., negative body evaluation; Bentz, Williamson, \& Smith, 1999; Williamson et al., 2004). Further, this covariation bias could be an additional distortion in cognitive processing that affects body evaluation, one that may influence how individuals perceive their interpersonal experiences and thus how individuals feel about their body.

In the present study, women completed a computer task wherein photos of their own body, of a control woman's body, and of a neutral object, were followed by nonverbal social feedback (i.e., facial crowds with equal numbers of negative, positive, and neutral faces). Images of faces are commonly used to simulate social feedback in research about social anxiety (Hirsch \& Clark, 2004) and have been shown to produce corresponding physiological responses in participants (e.g., photos of angry faces increase skin conductance responses; Dimberg, 1997; Merckelbach, van Hout, van den Hout, \& Mersch, 1989). After the computer task, women estimated the total percentage of negative, positive, and neutral social feedback that they thought followed their own body, the control woman's body, and the neutral object. This type of estimate, in which participants estimate the frequency that a stimulus (e.g., their body) is followed by a particular outcome (e.g., angry faces), is commonly used to investigate covariation bias (Hermann et al., 2004; Hirsch \& Clark, 2004; Tomarken et al., 1995).

Reflecting the proposed covariation bias, we hypothesised that women with a more negative body evaluation would estimate a higher level of negative social feedback for their own body. We included the additional stimuli (photos of the control woman and of the neutral object) to control for the selectivity of the covariation bias. In addition, we recorded how positively or negatively women rated the social feedback stimuli to test whether body evaluation also predicted the interpretation of the stimuli.

\section{Method}

\section{Participants}

Participants were 65 women aged between 18 and 30 years $(M=21.17, S D=2.60)$ with a self-reported body mass index (BMI) between 16.76 and $29.41(M=21.17, S D=2.42) .{ }^{1}$ The participants were students at a university in the south of the Netherlands, where the student population is predominantly Caucasian. A power analysis using G*Power (Faul, Erdfelder, Lang, \& Buchner, 2007) showed that the power achieved by this sample size was .73 .

\section{Materials}

Computer task. Participants received the following information on the computer screen: (a) in one of four quadrants they would see a photo of themselves, a photo of another woman (i.e., the control woman), or a photo of an object; (b) as soon as they saw the photo, they should click on it as quickly as possible; (c) after they clicked

\footnotetext{
1 Seventeen participants did not provide information about their height and/or weight, so their BMI could not be calculated.
}

on the photo, a group of portrait photos would briefly appear; and (d) Steps (a) to (c) would be repeated until they reached the end of the computer task.

The photos for Step (a) were three full-body photos of the participant, three full-body photos of a control woman, and three photos of a neutral object. Each photo was presented 30 times, for a sum of 270 trials. The control woman was a female university student of average build, dressed in a black t-shirt and pants. A standing lamp was chosen as the neutral object because it roughly resembled a human shape.

The photos used for Step (c) were different than those used for Step (a). The photos for Step (c) were chosen from the NimStim Facial Stimuli Set (Tottenham et al., 2009) and consisted of sets of portrait photos of nine Caucasian men and nine Caucasian women, chosen based on the highest validity for the emotions portrayed. There were portrait photos signalling negative (angry, mouth closed), positive (happy, mouth closed), and neutral (mouth closed) social feedback for each man and woman (54 portrait photos total). The portrait photos were arranged in a $4 \times 3$ matrix, which was presented for $400 \mathrm{~ms}$ per trial (Baccus, Baldwin, \& Packer, 2004). The matrix for each trial was different because the portrait photos that composed the matrices were randomised per participant. However, for each matrix the following rules were met: (a) there was an equal proportion of negative, positive, and neutral social feedback; (b) $50 \%$ of the portrait photos were of female faces; and (c) portrait photos could only appear once in each matrix. So, each matrix consisted of 12 portrait photos that were of six different women (two angry, two happy, two neutral) and six different men (two angry, two happy, two neutral). Each portrait photo was presented an equal number of times across the computer task.

Estimates of social feedback. Participants estimated the amount of negative, positive, and neutral social feedback that they perceived during the computer task, with regard to: (a) their own body, (b) the control woman's body, and (c) the neutral object (the lamp). Therefore, a total of nine estimates of social feedback were retrieved. An example of these items is, "All in all, how many (\%) of the portrait photos were positive (smiling) after the presentation of the photos of your own body?" Participants indicated their estimates on the computer by sliding a small tick across a bar ranging from $0 \%$ to $100 \%$. Each estimate of social feedback was given separately and the order of the questions was randomised per participant. To disguise the purpose of the study, we also included six filler estimates (e.g., about the percentage of portrait photos of women).

Body evaluation. The Multidimensional Body-Self Relations Questionnaire (MBSRQ; Brown, Cash, \& Mikulka, 1990; Cash, 2000) was used to measure trait body evaluation. The MBSRQ consists of 69 items (e.g., "I like my looks just the way they are") rated on 5-point scales ( $1=$ definitely disagree to $5=$ definitely agree). Only items from the Appearance Evaluation subscale (satisfaction with one's appearance; seven items) and the Body Areas Satisfaction Subscale (satisfaction with specific aspects of one's appearance; nine items) were used. As suggested by Cash (2000), we averaged the normalised Z-scores of these two subscales, with higher scores reflecting more positive body evaluation. The Appearance Evaluation Subscale and the Body Areas Satisfaction Subscale evidenced good internal consistency ( $\alpha=.88$ and .73) and one month test-retest reliability $(r=.91$ and .74$)$ in women over 18 years old (Cash, 2000). In the current sample, the internal consistency for the items of these two subscales together was $\alpha=.88$.

The Body Image States Scale (BISS; Cash, Fleming, Alindogan, Steadman, \& Whitehead, 2002) was used to measure state body evaluation. The BISS consists of six 9-point scale items that measure the following dimensions based on how the participant feels "right now, at this very moment:" (a) dissatisfaction-satisfaction with physical appearance, (b) dissatisfaction-satisfaction with body 
size and shape, (c) dissatisfaction-satisfaction with weight, (d) feelings of physical attractiveness-unattractiveness, (e) feelings about how one looks now compared to how one usually looks, and (f) evaluation of appearance in comparison to the appearance of others. The item scores are averaged, with higher scores reflecting a more positive state body evaluation. In an undergraduate sample, the BISS demonstrated acceptable internal consistency. Further, BISS scores were sensitive to positive and negative contexts and were highly correlated with scores on related measures (e.g., objectified body consciousness; Cash et al., 2002). Unfortunately, due to an error in our online research system, the BISS was delivered with a 7-point scale. For each item, only the first and last response options were labelled; the five response options in between were simply numbered. An example item is "Right now I feel..." where participants could choose a response option from $1=$ extremely dissatisfied with my physical appearance to $7=$ extremely satisfied with my physical appearance (response options 2 to 6 were numbered but unlabelled). In our sample, the internal consistency of this version of the BISS was good, $\alpha=.87$.

Facial ratings. Participants rated each of the 54 portrait photos that appeared in the computer task based on how they thought each person looked, using a 7 -point scale $(1=$ very angry to $7=$ very happy). They were instructed to rate each face separately and to not compare the faces with one another. Each portrait photo was presented separately, and the order in which the portrait photos were presented was randomised for each participant.

Mood. Participants rated their own mood using five visual analogue scales $(0=$ not at all to $100=$ very much) for the feelings happy, positive, energetic, sad (reverse scored), and anxious (reverse scored). Ratings were summed for a total score $(\alpha=.81$ in the present study), with higher scores reflecting a more positive mood.

\section{Procedure}

This study was approved by the ethical committee of Maastricht University. Participants were recruited by advertisements on campus or via the university's research website for a study about "facial recognition." Participants were tested individually in a university laboratory and all measures were completed on a computer. At Session 1, participants signed an informed consent sheet and then completed the measure of trait body evaluation. Afterward, the participants changed into a black t-shirt and pants that we provided for them, and were then photographed from the front and both sides in front of a white canvas. They were asked to stand with their arms at their sides and to look straight into the camera with a neutral expression. At Session 2 (one week later), participants completed the computer task, followed by the estimates of social feedback, the measures of mood and state body evaluation, and the facial ratings. The participants were aware that both sessions related to the same study. At the end of Session 2, they were asked to guess the purpose of the study ${ }^{2}$ and then they received a 10 Euro voucher or course credit for participation. The participants were debriefed via e-mail following completion of data collection.

\section{Statistical Analyses}

We conducted separate stepwise (backward) regression analyses to test the relations between women's body evaluation and estimates of social feedback (for their own body, for the control woman's body, and for the neutral object), as well as between body evaluation and the facial ratings. Separate analyses were performed

\footnotetext{
2 Two participants correctly guessed the purpose of the study. Their data were included in the study because their inclusion did not change any of the results.
}

for state and trait body evaluation and mood was included as a covariate in all analyses. For each analysis, all predictors (e.g., trait body evaluation and mood) were entered into the model at Step 1. At Step 2, any predictors that did not significantly contribute to the model were removed. All variables were treated as continuous variables. Normality of the error distribution was checked for all outcome variables prior to the analyses.

\section{Results}

\section{Primary Analyses of the Covariation Bias}

There were no missing data in the current study (aside from the aforementioned missing data with regard to BMI). Further, the errors for all outcome variables were normally distributed.

The results showed that women's trait body evaluation predicted their estimates of negative social feedback for their own body, $B=-7.57, t(63)=-2.20, p=.031, R^{2}=.07$. As expected, women with a more negative body evaluation gave higher estimates of negative social feedback for their own body. Note that mood was not a significant covariate $(p=.922)$ and had been removed from the model. Further, women's state body evaluation was not a significant predictor of negative social feedback for their own body, $B=-3.79$, $t(63)=-1.83, p=.072, R^{2}=.05$. Again, mood was not a significant covariate $(p=.817)$ and had been removed from the model.

\section{Secondary Analyses of the Covariation Bias}

To assess the selectivity of the covariation bias for negative social feedback, we repeated these analyses with participants' positive and neutral social feedback for their own body as outcome variables. Neither trait nor state body evaluation predicted estimates of positive social feedback for the own body (all ps > .10). However, trait body evaluation predicted estimates of neutral social feedback for the own body, $B=5.61, t(63)=2.03, p=.047, R^{2}=.06$, as did state body evaluation, $B=3.87, t(63)=2.37, p=.021, R^{2}=.08$. In sum, women with a more negative body evaluation gave lower estimates of neutral social feedback for their own body. For these analyses, as well, mood did not emerge as a significant covariate $(p=.576$ and $p=.910$, respectively).

We then investigated women's reported contingencies between the control woman's body and different kinds of social feedback, and between the neutral object and different kinds of social feedback. The results of these regression analyses were all nonsignificant (for both trait and state body evaluation; all ps > .097), indicating that the covariation bias was specific for the own body.

Next, we investigated whether body evaluation predicted the facial ratings for the negative, positive, and neutral social stimuli. Results of these regression analyses yielded nonsignificant findings for all types of social stimuli (all ps > .497). Therefore, body evaluation did not predict how the social stimuli were interpreted.

\section{Discussion}

The aim of the current study was to investigate whether women with negative body evaluation demonstrate a covariation bias for negative social feedback related to their own body. As predicted, we found that women with a more negative trait body evaluation estimated higher levels of negative social feedback related to their own body-even though there was absolutely no contingency between their own body and negative social feedback. We also confirmed that the covariation bias was specific for their own body and not for another woman's body or for a neutral object. In addition, we found that the covariation bias was not explained by differences in interpretation of the social feedback. 
The way individuals perceive social interactions, including the social feedback that they receive, has a profound influence on body image. In effect, these perceptions of interpersonal experiences form the "looking glass" through which individuals evaluate their body (Cash \& Fleming, 2002; Tantleff-Dunn \& Lindner, 2011). Distortions in cognitive processing can powerfully influence body image, as well, by reinforcing and maintaining existing negative body evaluation (Williamson et al., 2004). The covariation bias evidenced in the present study integrates the influence of distortions in cognitive processing and interpersonal experiences: it is possible that the tendency to perceive an association between the own body and negative social feedback when in fact there is none (read: covariation bias) has serious consequences for body image, both by "tainting" the looking glass through which women evaluate their body, and by confirming women's existing negative body evaluation. Another potential consequence of this covariation bias is that women may behave in ways that elicit negative social feedback, thereby further affecting their body evaluation (Cash \& Fleming, 2002).

It is important to note that we found that women with a more negative trait and state body evaluation estimated lower levels of neutral social feedback for their own body. One explanation could be that because women with a more negative body evaluation estimated higher levels of negative social feedback, they consequently estimated lower levels of neutral social feedback. However, this would not explain why women with a more negative body evaluation did not estimate lower levels of positive social feedback. Another possibility is that women with a more negative body evaluation filter social feedback dichotomously (i.e., social feedback is either negative or positive). This would reflect a broader tendency to engage in dichotomous thinking, which has been evidenced in previous research (Cash, 2011; Jakatdar et al., 2006).

Several limitations to this study must be noted. First, it is unclear whether the covariation bias for negative social feedback causes negative body evaluation, or vice versa. This limitation could be addressed by experimentally manipulating the covariation bias and investigating if body evaluation is affected. Second, the covariation bias might be explained by biased attention to negative social feedback. Running a similar experiment while registering women's eye movements could investigate this notion. Third, in research investigating covariation bias it is common to have participants estimate the frequency that a stimulus is followed by a particular outcome (e.g., De Jong et al., 1995; Hermann et al., 2004; Hirsch \& Clark, 2004). However, it remains to be determined whether women's estimates of negative social feedback inside the laboratory are equivalent to their perception of negative social feedback outside the laboratory. Fourth, another limitation concerns the measurement of state body evaluation after the computer task. It is possible that the computer task may have influenced participants' state body evaluation, for example via exposure to negative social feedback. Instead, state body evaluation could be measured immediately prior to the computer task, although participants may then be aware that the study concerns body image, which may influence their answers. Fifth, regarding our sample, our sample size was modest (the achieved power fell below .80), many participants did not provide us with information to calculate their BMI, and we did not collect information about participants' ethnicity. In addition, because we tested young women, our results cannot yet be extended to men or to other age groups. Lastly, we regret that we did not use the original version of the BISS (using a 9-point scale with each response option labelled) due to an error in our online research system.

Despite these limitations, the findings of this study have potential clinical implications. Specifically, our findings underscore the importance of addressing the social context in improving body evaluation. Namely, it may be important to address both women's thoughts about their body and women's thoughts about what others think about their body. Not addressing the latter thoughts may impede improvement in body evaluation (e.g., if women keep overestimating negative social feedback for their own body). However, it is an unanswered question whether women with a covariation bias for negative social feedback also demonstrate corresponding explicit thoughts (e.g., "Most people think that I am unattractive"). Another clinical implication of this study is that it may be important to use techniques designed to improve body evaluation that directly target social feedback. For instance, in an evaluative conditioning paradigm developed by Martijn, Vanderlinden, Roefs, Huijding, and Jansen (2010), participants' bodies were systematically paired with positive social feedback (smiling faces). Even though participants were unaware of the association between their own body and the positive social feedback, their body evaluation and self-esteem improved at post-test (the effect was specific for women high in body concern; see Martijn et al., 2010, for more details).

In sum, the current study provided evidence for a covariation bias for negative social feedback in women with a more negative body evaluation. Thereby we also integrated two domains, interpersonal experiences and cognitive processing, that play a pivotal role in determining how positively or negatively women feel about their body. Future research should address the aforementioned limitations to further delineate the covariation bias and its role in negative body evaluation. If additional support is found for the covariation bias, it will be an exciting next step to determine whether it can be unlearned to improve body evaluation in women.

\section{Acknowledgements}

We would like to thank Kai Karos and Gerard van Breukelen for their statistical advice and assistance, and Jacco Ronner for programming the computer task for this experiment. Further, the contribution of Jessica M. Alleva was supported by NWO grant 40410-118: Novel strategies to enhance body satisfaction.

\section{References}

Baccus, J. R., Baldwin, M. W., \& Packer, D. J. (2004). Increasing implicit selfesteem through classical conditioning. Psychological Science, 15, 498-502. http://dx.doi.org/10.1111/j.0956-7976.2004.00708.x

Bentz, B. G., Williamson, D. A., \& Smith, C. F. (1999). The prediction of negative events associated with anxiety and dietary restraint: A test of the content specificity hypothesis. Journal of Psychopathology and Behavioral Assessment, 21, 97-108. http://dx.doi.org/10.1023/A:1022110921090

Brown, T. A., Cash, T. F., \& Mikulka, P. J. (1990). Attitudinal body image assessment: Factor analysis of the Body-Self Relations Questionnaire. Journal of Personality Assessment, 55, 135-144. http://dx.doi.org/10.1207/s15327752jpa5501\&2_13

Carlson Jones, D. (2011). Interpersonal and familial influences on the development of body image. In T. F. Cash \& L. Smolak (Eds.), Body image: A handbook of science, practice, and prevention (pp. 110-118). New York, NY: Guilford Press.

Cash, T. F. (2000). Multidimensional Body-Self Relations Questionnaire users' manual (3rd rev.). Available from: www.body-images.com

Cash, T. F. (2011). Cognitive-behavioral perspectives on body image. In T. F. Cash \& L. Smolak (Eds.), Body image: A handbook of science, practice, and prevention (pp. 39-47). New York, NY: Guilford Press.

Cash, T. F., \& Fleming, E. C. (2002). Body image and social relations. In T. F. Cash \& T. Pruzinsky (Eds.), Body image: A handbook of theory, research, and clinical practice (pp. 277-286). New York, NY: Guilford Press.

Cash, T. F., Fleming, E. C., Alindogan, J., Steadman, L., \& Whitehead, A. (2002). Beyond body image as a trait: The development and validation of the Body Image States Scale. Eating Disorders: The Journal of Treatment and Prevention, 10, 101-113. http://dx.doi.org/10.1080/10640260290081678

Chapman, L. J., \& Chapman, J. P. (1967). Genesis of popular but erroneous psychodiagnostic observations. Journal of Abnormal Psychology, 72, 193-204. http://dx.doi.org/10.1037/h0024670

De Jong, P. J., Merckelbach, H., Arntz, A., \& Nijman, H. (1992). Covariation detection in treated and untreated spider phobics. Journal of Abnormal Psychology, 101, 724-727. http://dx.doi.org/10.1037/0021-843X.101.4.724

De Jong, P. J., Van Den Hout, M. A., \& Merckelbach, H. (1995). Covariation bias and the return of fear. Behaviour Research and Therapy, 33, 211-213. http://dx.doi.org/10.1016/0005 7967(94)E0024-D 
Dimberg, U. (1997). Psychophysiological reactions to facial expressions. In U. Segerstråle \& P. Molnár (Eds.), Communication. Where nature meets culture (pp. 47-60). Mahwah, NJ: Lawrence Erlbaum Associates.

Faul, F., Erdfelder, E., Lang, A. G., \& Buchner, A. (2007). G*Power 3: A flexible statistical power analysis for the social, behavioral, and biomedical sciences. Behavior Research Methods, 39, 175-191. http://dx.doi.org/10.3758/BF03193146

Fredrickson, B. L., \& Roberts, T. A. (1997). Objectification theory: Toward understanding women's lived experiences and mental health risks. Psychology of Women Quarterly, 21, 173-206. http://dx.doi.org/10.1111/j.1471-6402.1997.tb00108.x

Hermann, C., Ofer, J., \& Flor, H. (2004). Covariation bias for ambiguous social stimuli in generalized social phobia. Journal of Abnormal Psychology, 113, 646-653. http://dx.doi.org/10.1037/0021-843X.113.4.646

Hirsch, C. R., \& Clark, D. M. (2004). Information-processing bias in social phobia. Clinical Psychology Review, 24, 799-825. http://dx.doi.org/10.1016/j.cpr.2004.07.005

Jakatdar, T. A., Cash, T. F., \& Engle, E. K. (2006). Body-image thought processes: The development and initial validation of the Assessment of Body-Image Cognitive Distortions. Body Image, 3, 325-333. http://dx.doi.org/10.1016/j.bodyim. 2006.09.001

Martijn, C., Vanderlinden, M., Roefs, A., Huijding, J., \& Jansen, A. (2010). Increasing body satisfaction of body concerned women through evaluative conditioning using social stimuli. Health Psychology, 29, 514-520. http://dx.doi.org/ $10.1037 / \mathrm{a} 0020770$
Merckelbach, H., van Hout, W., van den Hout, M. A., \& Mersch, P. P. (1989). Psychophysiological and subjective reactions of social phobics and normals to facial stimuli. Behaviour Research and Therapy, 27, 289-294. http://dx.doi.org/ 10.1016/0005-7967(89)90048-X

Tantleff-Dunn, S., \& Lindner, D. M. (2011). Body image and social functioning. In T. F. Cash \& L. Smolak (Eds.), Body image: A handbook of science, practice, and prevention (pp. 263-270). New York, NY: Guilford Press.

Tomarken, A. J., Mineka, S., \& Cook, M. (1989). Fear-relevant selective associations and covariation bias. Journal of Abnormal Psychology, 98, 381-394. http://dx.doi.org/10.1037/0021 843X.98.4.381

Tomarken, A. J., Sutton, S. K., \& Mineka, S. (1995). Fear-relevant illusory correlations: What types of associations promote judgmental bias? Journal of Abnormal Psychology, 104, 312-326. http://dx.doi.org/10.1037/0021-843X.104.2.312

Tottenham, N., Tanaka, J., Leon, A. C., McCarry, T., Nurse, M., Hare, T. A., \& Nelson, C. A. (2009). The NimStim set of facial expressions: Judgments from untrained research participants. Psychiatry Research, 168, 242-249. http://dx.doi.org/10.1016/j.psychres.2008.05.006

Williamson, D. A., White, M. A., York-Crowe, E. \& Stewart, T. M. (2004). Cognitive behavioral theories of eating disorders. Behavior Modification, 28, 711-738. http://dx.doi.org/10.1177/0145445503259853 